\title{
Economía de la Agroindustrialización de la Papa en México
}

María de J. Santiago Cruz y José García Salazar ${ }^{2}$

\section{Resumen}

Después de breve síntesis de las tendencias en la producción, consumo, y comercio de la papa en México, se analiza la importancia de su industrialización en términos del valor de su producción frente a otros rubros en la manufacturera de alimentos y bebidas, y al personal empleado. Se examina también la liberación comercial de la papa dentro del tratado de libre comercio de Norte América incluyendo una descripción del sistema arancelcuota, así como los plazos de desgravación por tipo de producto. Se nota que la situación es bastante dinámica en particular en lo que se refiere al comercio exterior y que las implicancias de los arreglos comerciales pueden ser distintas por tipo y tamaño de productor. Así, es necesario que la política agrícola proporcione al cultivo de papa un tratamiento integral y bajo la perspectiva de una cadena económica que diferencie entre aquellas iniciativas para los productores con potencial comercial y aquellas que para los que no pueden seguir en el mercado.

\section{Introducción}

La papa es una de las principales hortalizas producidas en México. En 1998 se cosecharon 1.27 millones de toneladas en una superficie de 63,000 ha (FAO. Statistical Issues). El rendimiento promedio nacional fue de $20.2 \mathrm{t} / \mathrm{ha}$.

México tiene un consumo anual promedio de papa de $12 \mathrm{~kg}$ por habitante, el más bajo en América Latina y mucho menor que el consumo promedio en Europa, que es de $86 \mathrm{~kg}$ por persona. Pero es tal vez el crecimiento de la población el principal factor que explicaría el incremento en la producción que se ha observado en las décadas recientes, y en menor medida, el cambio en los patrones de consumo, con la inclusión de mayores cantidades de papa en la dieta mexicana.

\footnotetext{
${ }^{1}$ Economista, PhD, Profesor Investigador en el Programa de Economía, Instituto de Socioeconomía, Estadística e Informática, Colegio de Postgraduados en Ciencias Agrícolas. Correo electrónico: ecomjs@colpos.mx

${ }^{2}$ PhD en Ciencias con especialidad en Economía, Profesor Investigador Asociado en el Programa de Economía, Instituto de Socioeconomía, Estadística e Informática, Colegio de Postgraduados en Ciencias Agrícolas.

Correo electrónico: jsalazar@colpos.colpos.mx
} 
El incremento en la producción total de papa ha sido continuo, aunque no así la magnitud de la superficie cultivada (Figura 1). En el periodo 196079 es cuando se registraron aumentos considerables en el área cultivada, habiendo pasado de 48,832 a 87,075 ha en dichos años. La superficie del año 1979 puede considerarse como el punto máximo en cuanto a superficie. Posterior a esa fecha ha habido una reasignación de la superficie cultivada en la agricultura mexicana, en detrimento del cultivo de la papa. Así, en la década de los 80 y de los 90 pueden constatarse fluctuaciones de año en año, con una ligera tendencia a la baja, pues en 1998 la superficie con este cultivo alcanzó 63,000 ha

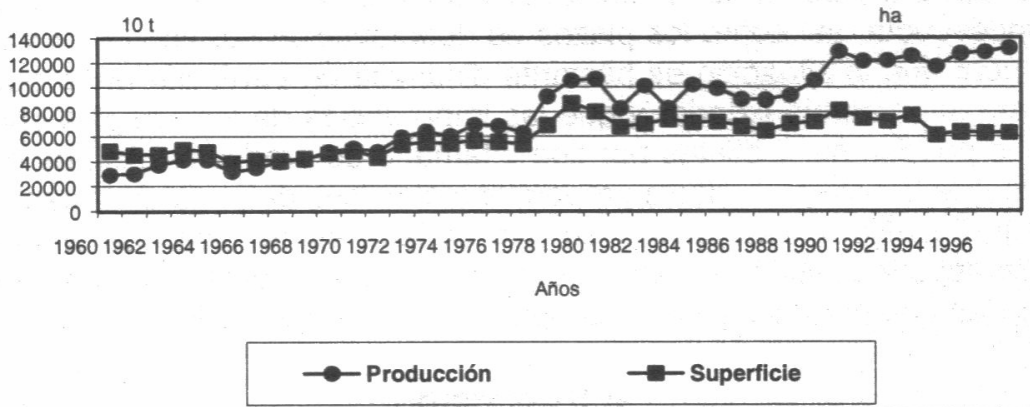

Figura 1. Producción y superficie de papa, 1997

Pero mientras la superficie cultivada ha tenido fluctuaciones, el volumen de la producción total ha aumentado, debido a un continuo incremento en el rendimiento por unidad de superficie. Este aumento en la producción se explica principalmente por la incorporación de innovaciones tecnológicas que contrarrestan los problemas fitosanitarios, así como el mejoramiento en las técnicas de manejo del cultivo.

En el Cuadro 1 se presenta la información correspondiente a rendimientos observados en los cinco principales Estados productores de papa en México. La producción de estas cinco entidades comprende el $54 \%$ de la producción total nacional. Hay un dato adicional que es pertinente tener en mente al analizar el siguiente cuadro. Mientras que en los Estados de Sinaloa y Nuevo León se produce exclusivamente papa blanca, en los Estados de México, Guanajuato y Puebla también se produce la variedad "rosita", aunque esto es llevado a cabo principalmente por los pequeños productores y en parte por los medianos 
Revista Latinoamericana de la Papa. 2001. Vol-especial:21-43

Cuadro1. México: Rendimiento de papa en los principales Estados productores 1990-96 (tha).

\begin{tabular}{|ccccccccc|}
\hline Estado & $\mathbf{1 9 9 0}$ & $\mathbf{1 9 9 1}$ & $\mathbf{1 9 9 2}$ & $\mathbf{1 9 9 3}$ & $\mathbf{1 9 9 4}$ & $\mathbf{1 9 9 5}$ & $\mathbf{1 9 9 6}$ & $\begin{array}{c}\text { Tasa } \\
\text { de } \\
\text { crecimiento }\end{array}$ \\
\hline Sinaloa & 22.9 & 19.4 & 14.2 & 16.1 & 22.6 & 22.3 & 23.4 & 0.3 \\
México & 14.8 & 14.4 & 15.2 & 17.4 & 16.2 & 19.5 & 19.7 & 5.4 \\
Puebla & 9.4 & 10.6 & 12.1 & 11.4 & 10.0 & 12.1 & 11.1 & 3.0 \\
Guanajuato & 23.4 & 22.1 & 25.5 & 22.2 & 29.6 & 23.5 & 26.6 & 2.3 \\
Nuevo León & 30.5 & 35.1 & 36.9 & 31.5 & 34.5 & 32.0 & 32.2 & 0.9 \\
$\begin{array}{c}\text { Promedio } \\
\text { Nacional }\end{array}$ & 15.8 & 16.2 & 16.8 & 16.9 & 19.1 & 19.9 & 20.4 & 4.8 \\
& & & & & & & & \\
\hline
\end{tabular}

Fuente: Apoyos y servicios a la Comercialización Agropecuaria (ASERCA), con datos de la Secretaría de Agricultura. Ganadería y Desarrollo Rural.

De los datos del Cuadro 1 se desprenden dos hechos. Por una parte, que la tasa de crecimiento promedio nacional incluye crecimientos regionales heterogéneos, siendo dicho crecimiento menor en los Estados norteños del país, en donde predomina la producción bajo riego, así como los productores medianos y grandes. Por otra parte, los rendimientos promedio entre Estados son disímiles, con los menores en el Estado de Puebla, lugar de tradición papera, pero también donde, respecto a los demás Estados, se encuentran mayoritariamente en las estructura productiva los productores pequeños y medianos.

La producción de papa en México tiene características diferentes, según se trate de papa blanca o papa rosa, respecto a rendimientos por hectárea, sistemas de producción y características del producto, como contenido de harina, textura, sabor y adecuación para el procesamiento industrial. Igualmente, la producción de una u otra variedad, pero principalmente de la papa blanca y la papa rosa, se lleva a cabo por diversos tipos de productores.

Cuadro 2. México: Producción de papa blanca y rosa (\%), según tipo de productor

\begin{tabular}{|ccccc|}
\hline Variedad & Pequeño & Mediano & Grande & Total \\
\hline Alpha (blanca) & 29 & 50 & 69 & 60 \\
Rosita (rosa) & 69 & 27 & 0 & $1 S$ \\
Otras variedades & 2 & 23 & 31 & 25 \\
(blancas) & 100 & 100 & 100 & 100 \\
Total & & & & \\
\hline
\end{tabular}

Fuente: SAGAR/INIFAP. 1997. Programa Nacional de Investigación en el Cultivo de la Papa. Publicación Especial Núm. 13 (Abril). México, D.F 
La papa en sus variedades "rosita" se consume principalmente en fresco, en el mercado interno; parte de ella se usa para semilla, para los ciclos posteriores. La papa blanca en sus diferentes variedades, se consume en fresco, últimamente también se exporta, aunque en cantidades mínimas, parte de ella se usa para semilla y otra parte se procesa industrialmente.

\section{Costos de producción}

La papa es un cultivo intensivo en uso de agroquímicos y está parcialmente mecanizado. Estimaciones recientes indican que una hectárea de papa requiere entre 50 y 100 jornales, variando entre regiones, según calidad de la papa producida, el rendimiento obtenido, las características del terreno cultivado y el tipo de productores.

Informaciones actuales ubican el costo total por hectárea variando según el tipo de productores en la relación de 1-1.8-2.9 entre productores pequeños, medianos, y grandes. Esta diferencia, que como se ve, significa los menores costos de producción por hectárea para los pequeños productores, se explica por el uso de paquetes tecnológicos específicos que comprenden un uso diferente de agroquímicos, de mano de obra y de densidad de siembra. Esa situación se explica también por el hecho de que en los sistemas de producción de los pequeños productores, se considera en su mayoría la producción de papa de temporal, donde el cultivo se lleva a cabo con la humedad residual del suelo, por lo que en su estructura de costos no se contempla el costo de operación del agua.

La posición competitiva de los productores de papa es heterogénea. Estudios hechos en una importante región productora del Centro de México revelaron que la capacidad de respuesta ante el reto que significa la apertura comercial en este rubro, podría ser enfrentada exitosamente por los medianos productores (Santiago y Ruwalcaba 1995).

Hay elementos que caracterizan la situación productiva de la papa y que habrán de tomarse en cuenta en la evaluación de las perspectivas de agroindustrialización de este producto en el futuro. A ese respecto hay que mencionar en principio la división entre papa blanca y papa "rosita", la calidad de la producción, la estructura de los costos de producción según tipo de productores, así como la infraestructura comercial, conocimiento y facilidad de acceso a mercados disponible a cada uno de ellos, o como organización de productores, como los elementos centrales que seguramente jugarán un papel central a este respecto.

El marco regulatorio del Tratado de Libre Comercio con América del Norte (TLCAN) prevée una desregulación arancelaria total de la importación de papa hacia el año 2003. Esta desregulación se ha planteado en forma gradual, con cuotas de importación variables en el tiempo 
Cuadro 3. México: Estructura de los costos variables de producción de la papa por hectárea, según tipo de productor, 1998

(En porcentajes)

\begin{tabular}{|lccc|}
\hline Insumo & \multicolumn{3}{c|}{ Tipo de productores } \\
\hline Semilla & Pequeño & Mediano & Grande \\
Agroquímicos & 47.95 & 35.13 & 32.71 \\
Mano de obra & $39.06^{*}$ & 43.15 & 48.16 \\
Renta de la tierra & 11.54 & 16.98 & 13.21 \\
Operación del riego & 1.45 & 2.76 & 2.40 \\
Total & -- & 1.98 & 3.52 \\
& 100.00 & 100.00 & 100.00 \\
\hline
\end{tabular}

Fuente: Quaim, 1998.

Los retos que esta apertura comercial plantea a los productores, puede generar diversas capacidades de respuesta, basadas en los costos de producción y en las ventajas competitivas de los diferentes tipos de productores. En algunos estudios se prevé una posible ventaja productiva para la papa blanca de los medianos productores (Santiago y Ruvalcaba, 1995), dato al que habría que agregar los otros elementos que componen la ventaja competitiva, como son la infraestructura en comunicaciones, en tecnología comercial y conocimiento del mercado de cada tipo de productor.

La apertura comercial que prevé el TLCAN significará una apertura traducida en una competencia entre productores domésticos y extranjeros. Como se ha mencionado antes, en la capacidad de respuesta intervienen tanto factores productivos como factores institucionales y de infraestructura. Respecto a la situación productiva se tiene el siguiente panorama:

A pesar de la desventaja de costos y rendimientos de los productores mexicanos, la posibilidad de sustitución entre producción interna y producción externa en el mercado mexicano de papa fresca tiene algunas facetas que es necesario tener presente.

El consumo mexicano está orientado hacia la variedad Alpha y la variedad Rosita, mientras que en los Estados Unidos la variedad mayormente producida es la Russet Burbank y no se produce la variedad rosa. Por otro lado, la producción de los Estados Unidos es en otoño, mientras que en México se cosecha el producto durante todo el año en las diversas regiones; situación que haría posible, cumpliendo con la calidad requerida, iniciar exportaciones de México a los Estados Unidos. Puede verse, por lo tanto, que el comercio exterior de papa fresca, tanto de los Estados Unidos hacia México, como en el sentido opuesto, es posible; sin embargo, por una parte se requeriría ajustes en los gustos y preferencias de los consumidores mexicanos, en el caso de importar papa de Estados Unidos, por otro lado se requeriría por parte de los productores mexicanos ajustes en sus tecnologías de producción y en los controles de calidad. Ambos factores son susceptibles de realizarse, pero requieren tiempo 
Cuadro 4. Costos de producción de papa en México y en los Estados Unidos, 1998

(En pesos mexicanos de 1998)

\begin{tabular}{|cccccc|}
\hline & México & \multicolumn{5}{c|}{ Estados Unidos de América } \\
\hline & Pequeños & Medianos & Grandes & Idaho & North Dakota \\
\hline $\begin{array}{c}\text { Costo total/ha } \\
\text { Rendimiento } \\
\text { (t/ha) }\end{array}$ & $12,935.83$ & $23,375.69$ & $38,112.98$ & $33,576.37$ & $23,141.04$ \\
$\begin{array}{c}\text { Costo por ton } \\
\text { producida }\end{array}$ & $1,165.39$ & 20.86 & 31.75 & 38.90 & 27.60 \\
\hline Fuente: Quaim,1998. & $1,120.46$ & $1,200.41$ & 863.15 & 838.44 \\
\hline
\end{tabular}

\section{El consumo nacional de papa y el comercio exterior}

De acuerdo con las estimaciones del consumo nacional aparente de papa, en el periodo 1990-98 este indicador presentó un comportamiento muy regular, con una tasa promedio anual de crecimiento de $1 \%$, al pasar de 1,297 a 1,314 millones de toneladas. En general, el consumo osciló entre 1,162 y 1,359 millones de toneladas, con niveles mínimos en 1993 y máximos en 1997, respectivamente (Cuadro 5).

En promedio, en el periodo 1990-98 el consumo nacional aparente de papa fue de 1,268 millones de toneladas, de las cuales $97.5 \%$ (1,239 millones de toneladas) fue cubierto con producción interna y el restante $2.5 \%(32,0001)$ con importaciones

Cuadro 5. Consumo nacional aparente de papa, 1990-98. (000 t)

\begin{tabular}{|ccccc|}
\hline Año & Producción & Consumo & Exportació & Importación \\
\hline 1990 & 1,286 & 1,297 & 3 & 14 \\
1991 & 1,211 & 1,243 & 1 & 33 \\
1992 & 1,213 & 1,235 & 2 & 24 \\
1993 & 1,134 & 1,163 & 2 & 31 \\
1994 & 1,167 & 1,199 & 1 & 32 \\
1995 & 1,269 & 1,293 & 1 & 25 \\
1996 & 1,282 & 1,318 & 1 & 37 \\
1997 & 1,317 & 1,360 & 2 & 46 \\
1998 & 1,272 & 1,314 & 1 & 43 \\
Promedio & 1,239 & 1,269 & 2 & 32 \\
\hline
\end{tabular}

Fuente: FAOSTAT (www.apps.fao.org) 
La distribución del consumo según destino fue la siguiente: el $80.6 \%$ fue consumido por la población humana, el $5.4 \%$ fue procesado por la industria productora de papas fritas, el $10.9 \%$ se utilizó como semilla y el restante $3.1 \%$ se perdió por mermas en el proceso de comercialización del producto (Cuadro 6).

Se observan cambios en la estructura del consumo según destino. La participación del consumo de papa para la industria ha aumentado y la participación del consumo para semilla ha disminuido, en tanto que los otros dos rubros se han mantenido estables. El crecimiento del consumo de productos "chatarra" por amplios grupos de la población, que incluyen con creces a la población mexicana de más bajos recursos, explica el crecimiento de la producción de papas fritas, en tanto que el descenso de la superficie sembrada explica la disminución del consumo de papa para siembra.

Cuadro 6. Consumo de papa según uso final, 1990-98

(En porcentajes)

\begin{tabular}{|cccccc|}
\hline Año & Consumo & Humano & Procesada $^{1}$ & Semillas $^{2}$ & Mermas $^{3}$ \\
\hline 1990 & 100.0 & 80.5 & 3.5 & 12.8 & 3.2 \\
1992 & 100.0 & 80.6 & 4.1 & 12.3 & 3.1 \\
1993 & 100.0 & 80.4 & 4.5 & & 3.1 \\
1994 & 100.0 & 79.8 & 5.2 & 11.8 & 3.1 \\
1995 & 100.0 & 81.0 & 5.6 & 10.3 & 3.1 \\
1996 & 100.0 & 81.1 & 5.6 & 10.1 & 3.1 \\
1997 & 100.0 & 81.5 & 5.7 & 9.6 & 3.1 \\
1998 & 100.0 & 80.8 & 6.4 & 9.6 & 3.1 \\
1999 & 100.0 & 79.6 & 7.5 & 9.8 & 3.1 \\
Promedio & 100.0 & 80.6 & 5.4 & 10.9 & 3.1 \\
\hline
\end{tabular}

${ }^{1}$ El consumo de papa para procesamiento se obtuvo multiplicando la producción de papa frita por el factor de conversión de papa frita a papa fresca.

${ }^{2}$ El consumo de papa para semilla se calculó multiplicando la superficie sembrada de papa por la densidad de siembra por hectárea.

${ }^{3}$ Se consideró que el $3.2 \%$ de la producción se pierde por mermas.

Fuente: Elaborado con información obtenida de: FAOSTAT (www.apps.fao.org/) e INEGI (www.inegi.gob.mx/).

\section{Importaciones}

Este renglón es de poca importancia ya que el $97.5 \%$ del consumo- de papa se abastece con producción nacional. En promedio, las importaciones fueron de 32 mil toneladas en el periodo 1990-98. Sin embargo, es importante mencionar que las importaciones han sostenido una tendencia que ha sido ascendente y progresiva, a tal grado que en los años de 1997 y 1998 las compras al exterior abastecieron más de $3 \%$ del consumo aparente del producto (Cuadro 6) 
Las fracciones arancelarias para las importaciones de la papa son cuatro:(a) la 0701.10.01 para papas frescas o refrigeradas para siembra,

(b) la 0701.90.99 para papas frescas o refrigeradas para los demás usos,

(c) la 0710.10 .01 para papas cocidas en agua o al vapor, congeladas y,

(d) la 0712.10.01 para papas cortadas en trozos o en rodajas, pero sin otra preparación.

De las cuatro fracciones arancelarias, las papas frescas o refrigeradas para los demás usos son las que ocupan el primer lugar en las importaciones, tanto en valor como en volumen. En promedio, en los años para los cuales se reporta información, las importaciones de esta fracción fueron de 25,000 t. Les siguieron, en orden de importancia, las papas para siembra, las cocidas y por último las cortadas (Cuadro 7).

Cuadro 7. Cantidad y precio unitario de las importaciones de papa por fracción arancelaria, 1990-98

\begin{tabular}{|c|c|c|c|c|c|c|c|}
\hline Año & Siembra & $\begin{array}{c}\text { Demás } \\
\text { usos } \\
\text { Tol }\end{array}$ & Cocidas & Cortadas & $\begin{array}{r}\text { Siembra } \\
\text { Dól }\end{array}$ & Dólares por tonelada & $\begin{array}{l}\text { Cocidas } \\
\text { ada }\end{array}$ \\
\hline 1990 & 10,305 & 3,259 & 953 & 24 & 262.7 & 228.2 & 803.2 \\
\hline 1991 & $\mathrm{Nd}$ & nd & nd & nd & nd & nd & nd \\
\hline 1992 & 7,782 & 28,676 & 3,570 & 53 & 358.0 & 222.0 & 720.1 \\
\hline 1993 & 24 & 31,329 & 5,177 & 5 & 371.5 & 251.3 & 782.8 \\
\hline 1994 & 9 & 32,239 & 6,742 & 72 & 371.5 & 284.8 & 791.7 \\
\hline 1995 & 16 & 24,664 & 3,860 & 18 & 378.3 & 286.9 & 697.0 \\
\hline 1996 & 9,303 & 27,247 & 3,556 & 38 & 385.0 & 282.5 & 776.4 \\
\hline 1997 & 13,023 & 32,477 & 2,909 & 70 & 365.9 & 225.0 & 733.2 \\
\hline 1998 & nd & nd & $\mathrm{Nd}$ & nd & nd & nd & nd \\
\hline Prom & 5,780 & 25,699 & 3,824 & 40 & 356 & 254 & 758 \\
\hline
\end{tabular}

Nota: nd=no disponible. El promedio de volumen y precios corresponde a los siete años para los cuales existe información.

Fuente: Elaborado con información obtenida de: INEGI. 1990 a 1997. Anuario Estadístico de Comercio Exterior de los Estados Unidos Mexicanos. México. D.F. SECOFI (www.secofi.snci.gob.mx/aracom/cgi).

Dado que las empresas agroindustrializadoras de papa se abastecen principalmente con la producción nacional, cabe suponer que las empresas importadoras de papa destinan dicha mercancía importada directamente para la distribución al consumo final y ocasionalmente para la agroindustrialización. La importación que pudieran hacer las grandes empresas agroindustrializadoras de papa para procesar es un aspecto que se define en el precio y la calidad requeridos. Informaciones actuales señalan que el precio pagado al productor nacional de dichas empresas es de aproximadamente US\$240/t, cantidad inferior a la que pagarían por una tonelada importada, de cualquier fracción arancelaria de las cuatro existentes (Cuadro 7) 
Las importaciones de papa para siembra presentaron un comportamiento muy irregular en el periodo 1990-98. En 1994, por ejemplo, las compras externas sólo fueron de 91 en tanto que en 1990 y 1997 fueron mayores a 10,0001. La producción nacional de papa para siembra explica el comportamiento de las importaciones ya que los productores nacionales recurren al mercado externo sólo cuando la producción de semilla es insuficiente para abastecer el consumo. Las importaciones del resto de las fracciones arancelarias presentó un comportamiento más regular en el periodo.

Respecto a los precios de importación, el grado de procesamiento del producto que se importa establece la diferencia del precio unitario. En general, la papa fresca o refrigerada para los demás usos, es más barata que la papa para siembra y que la papa cocida y cortada; por ejemplo, en 1997 los precios de la papa para siembra y cocida fueron respectivamente mayores en $62.7 \%$ y $225.8 \%$ al precio de la papa para los demás usos.

\section{Exportaciones}

En el caso de las exportaciones, las estadísticas señalan que este rubro es apenas perceptible, ya que durante los últimos ocho años no han llegado ni siguiera al 1\% del total de la producción nacional.

Son tres las fracciones arancelarias para las exportaciones de papa: (a) la 0710.10 para papas cocidas en agua o vapor congeladas, (b) la 200410 para papas preparadas o conservadas (excepto en vinagre 0 ácido acético) congeladas y, (c) la 200520 para papas preparadas o conservadas (excepto en vinagre o en ácido acético) sin congelar.

Las mayores exportaciones corresponden a la fracción 200520, y de acuerdo a los datos registrados durante los últimos años, éstas se han dirigido principalmente a Belice, el cual ha absorbido más del $90 \%$ de las exportaciones, aunque también se han realizado envíos a otros países de América Latina. Según estadísticas de la FAO, el nivel de rendimiento promedio de papa en México es de apenas 20 toneladas por hectárea contra 38 y 43 toneladas por hectárea en los Estados Unidos y los Países Bajos, respectivamente.

\section{Precios}

El análisis de diversos niveles de precios al productor permite establecer algunas conclusiones importantes acerca del mercado de la hortaliza. Existe un amplio margen de comercialización entre el precio medio rural y los precios al mayoreo y de la papa frita. En 1997, por ejemplo, el precio al mayoreo en las centrales de abasto del Distrito Federal, Monterrey y Guadalajara fue mayor en $51.2,57.6$ y $43.5 \%$ al precio medio rural nacional, respectivamente. En este mismo año el precio de la papa frita fue 19.4 veces el precio medio rural 
Cuadro 8. Volumen de exportaciones de papa por fracción arancelaria, 1990-97

\begin{tabular}{|ccccc|}
\hline Año & Cocidas & $\begin{array}{c}\text { Preparadas } \\
\text { congeladas } \\
\text { Toneladas }\end{array}$ & $\begin{array}{c}\text { Procesada } \\
\text { sin congelar }\end{array}$ & Total \\
\hline 1990 & 7 & 0 & 51 & 57 \\
1991 & nd & nd & nd & Nd \\
1992 & 0.03 & 1 & 18 & 19 \\
1993 & 1 & 0.01 & 76 & 77 \\
1994 & 12 & 1 & 201 & 214 \\
1995 & 19 & 1 & 517 & 537 \\
1996 & 0.3 & 0.2 & 693 & 649 \\
1997 & 16 & 18 & 715 & 749 \\
Promedio & 8 & 3 & 324 & 335 \\
\hline
\end{tabular}

Nota: $\quad$ nd=no disponible. El promedio de volumen y precios corresponde a los siete años para los cuales existe información.

Fuente. Elaborado con información obtenida de: INEGI. 1990 a 1997. Anuario Estadístico de Comercio Exterior de los Estados Unidos Mexicanos.México. D.F.

Los mecanismos de comercialización de la papa en el país tienen marcadas diferencias, las cuales están en función de las características de las unidades productoras, del grado de organización de los agricultores, de la infraestructura de almacenaje con que se cuenta y del destino final que tendrá el producto.

Según ASERCA (1998) los canales de comercialización que se pueden ubicar en dos de las entidades con mayor producción de papa son los siguientes. En el caso de Sinaloa, un Estado productor del Pacifico Norte, con grandes productores, existen cinco canales de comercialización: (a) los productoresbodegueros, que son aquellos que por sus grandes volúmenes de producción cuentan con locales en centrales de abasto, (b) los productores que no cuentan con bodega, pero que envían su producto a las centrales de abasto, en donde previamente han definido un precio, el cual depende de las condiciones en la que se encuentra el mercado. En este caso los agricultores corren con el gasto de transportación del producto, (c) Los comercializadores independientes o aquellos que compran la producción de papa en el campo, que en el caso de Sinaloa se da fundamentalmente en el sector ejidal, (d) El cliente industrial, que es el que compra directamente a los productores para la industria de frituras, en este caso hablamos de las grandes firmas o bien de industrializadores locales y, (e) El cliente institucional, que comprende a aquellos que compran de manera directa a los productores para satisfacer la demanda de escuelas y hospitales, etc 
En el Estado de México, entidad localizada en el Centro, con productores medianos, grandes y pequeños, la comercialización está íntimamente relacionada a la forma de producción en donde la figura de "mediero" es fundamental. El mediero es la persona que puede ser o no de la región, pero quien comparte la mitad de los gastos de producción y en consecuencia le corresponde la mitad de la cosecha y de la ganancia. De esta forma de producción se desprenden tres canales de comercialización en el Estado: (a) los productores ejidales o particulares y/o medieros, que venden directamente a la Central de Abastos y que entregan su producto a alguna bodega a través de un trato previo del precio y de las condiciones que deberá tener la hortaliza; (b) los productores ejidales o particulares y/o medieros, también venden directamente a la Central de Abastos, pero a través del mecanismo del mercado de subasta, en donde mediante un proceso de negociación se determina el precio de acuerdo a las condiciones de oferta y demanda que imperen en el mercado y, (c) los comercializadores independientes, que son aquellos que en etapas de baja producción llegan directamente a las zonas productoras y pagan el producto a pie de parcela, incluso sin tomar en cuenta la calidad del mismo.

En las dos primeras formas de comercialización la participación del llamado agente "cotizador" es un mecanismo fundamental para obtener un mayor dinamismo y mejores condiciones en este proceso. Los cotizadores son personas elegidas en la región que tienen como objetivo principal conciliar entre los productores y los bodegueros el mejor precio para ambas partes. Este mecanismo es bastante positivo para los productores en épocas o años en los que la producción es baja, pero cuando hay una sobreoferta y los precios caen, su participación resulta muy limitada, ya que este agente no cuenta con mecanismos que le permitan una mejor negociación. En el Estado de México la industria no se hace presente, ya que una buena parte de la producción de papa es de color, la cual no es idónea para frituras.

Las más importantes Centrales de Abasto, cercanas a las principales regiones productoras y cuyos precios son líderes en el mercado, son cuatro" La Central de Abastos de la Ciudad de México, la de Guadalajara (Pacífico Norte), la de Puebla (Centro Sur) y la de Monterrey (Noreste).

Es importante señalar que en la Central de Abastos de la Ciudad de México existe un proceso de concentración de parte de algunos bodegueros, los cuales comercializan importantes volúmenes de papa. Informaciones recientes señalan la existencia de seis grandes bodegueros, los cuales concentraban el $60 \%$ del volumen total en esa Central de Abasto.

Los amplios márgenes de comercialización obedecen al bajo poder de negociación de los productores agrícolas de papa en el proceso de compra venta del producto (Cuadro 9). 
Cuadro 9. Niveles de precio de la papa, 1993-97

\section{(Pesos de 1994 por tonelada)}

\begin{tabular}{|cccccc|}
\hline \multirow{2}{*}{ Año } & \multirow{2}{*}{ Medio rural } & \multicolumn{3}{c|}{ Mayoreo } & \multirow{2}{*}{ Papa frita } \\
\cline { 3 - 5 } & & DF & Monterrey & Guadalajara & \\
\hline 1993 & 945 & 2,055 & 1,943 & 1,680 & Nd \\
1994 & 1,730 & 2,929 & 3,167 & 1,679 & 25,496 \\
1995 & 1,312 & 1,991 & 2,182 & 1,975 & 23,650 \\
1996 & 1,338 & 2,115 & 2,157 & 2,154 & 22,560 \\
1997 & 988 & 1,495 & 1,558 & 1,419 & 19,191 \\
\hline
\end{tabular}

${ }^{1}$ El precio de la papa frita corresponde al precio unitario que se obtiene dividiendo el valor de la producción entre volumen de papa frita producida. El precio al mayoreo corresponde al promedio anual. Para obtener los precios reales se utiliza el índice de precios al consumidor.

Fuente: Elaborado con información de: SAGAR. 1993 a 1997. Anuario estadístico de la producción agrícola de los Estados Unidos Mexicanos. México, D.F. ASERCA. Varios números. Canasta Agropecuaria. México. D.F. INEGI (www.inegi.gob.mx/)

Haciendo comparaciones de los precios al mayoreo entre las centrales de abasto se puede observar que la de Monterrey es la que mayores precios presenta; en 1997, el precio al mayoreo en Monterrey fue mayor en $4.2 \%$ al registrado en el DF y $9.8 \%$ mayor al que se registró en Guadalajara. Parece ser que el factor que explica la diferencia espacial en precios es la cercanía a las zonas productoras, pues Guadalajara es el centro de consumo más cercano a Sinaloa y el Distrito Federal a los Estados de México y Puebla.

En el periodo de análisis puede observarse una disminución en los precios reales tanto en el medio rural como en los niveles al mayoreo y de las papas fritas. Desde 1994, el crecimiento de la inflación fue mayor al observado por los precios de la papa en sus diferentes niveles. Después de 1994 el nivel más bajo se observó en 1997, donde el precio medio rural de la papa fue de apenas 988 pesos de 1994 por tonelada.

\section{La industrialización de la papa en México}

En el Cuadro 10 se presenta el valor de la producción de la industria manufacturera de alimentos y bebidas que arroja la Encuesta Industrial Mensual levantada por el Instituto Nacional de Estadística, Geografía e Informática. Durante el periodo 1994-98 el valor promedio de la industria fue de 109,413 millones de pesos de 1994, observándose una ligera disminución en el valor de 1996 a 1998 
Revista Latinoamericana de la Papa. 2001. Vol-especial: 21-43

Cuadro 10. Valor de la producción de la Industria manufacturera de alimentos, bebidas, y otros. 1994-98 (Millones de pesos de 1994)

\begin{tabular}{|lcccc|}
\hline Clase & 1994 & 1996 & 1998 & Promedio \\
\hline Total & 107,461 & 114,141 & 108,114 & 109,413 \\
Preparación de conservas y embutidos de carne & 3,147 & 3,036 & 3,163 & 3,118 \\
Tratamiento y envasado de leche & 5,419 & 5,921 & 7,040 & 6,133 \\
Elaboración de crema, mantequilla y queso & 3,177 & 3,174 & 3,305 & 3,192 \\
Elaboración de leche condensada, evaporada y en polvo & 3,136 & 3,116 & 2,930 & 2,957 \\
Preparación y envasado de frutas y legumbres & 3,520 & 3,612 & 4,233 & 3,764 \\
Tostado y molienda de café & 347 & 293 & 235 & 304 \\
Molienda de trigo & 2,695 & 5,023 & 2,898 & 3,561 \\
Elaboración de harina de maíz & 2,492 & 3,350 & 2,039 & 2,530 \\
Elaboración de galletas y pastas alimenticias & 2,232 & 2,639 & 2,255 & 2,373 \\
Panadería y pastelería industrial & 4,364 & 4,708 & 5,176 & 4,708 \\
Fabricación de aceites y grasas vegetales comestibles & 6,860 & 8,655 & 7,175 & 7,800 \\
Elaboración de azúcar y productos residuales del café & 6,463 & 7,945 & 6,415 & 6,985 \\
Elaboración de concentrados, jarabes y colorantes & 3,462 & 3,633 & 4,087 & 3,696 \\
naturales & & & 4,603 & 4,505 \\
Elaboración de botanas y productos de maíz no & 5,019 & 4,290 & 4,63 & 990 \\
Papas fritas (valor) & 946 & 954 & 1,135 & 5,321 \\
Papas fritas (volumen en toneladas) & 37,822 & 42,270 & 55,321 & 45,261 \\
Preparación y mezcla de alimentos para animales & 5,679 & 6,657 & 5,434 & 5,886 \\
Fabricación de cerveza & 9,393 & 8,594 & 9,300 & 8,867 \\
Elaboración de refrescos y otras bebidas no alcohólicas & 14,413 & 13,400 & 14,370 & 13,844 \\
Fabricación de cigarros & 6,357 & 6,288 & 4,213 & 5,618 \\
\hline
\end{tabular}

Fuente: Elaborado con información de: INEGI (www.inegi.gob.mx.) 
Las clases de alimentos que más importancia tienen en la industria agroalimentaria son la elaboración de refrescos y otras bebidas no alcohólicas, participando con el $12.7 \%$ del valor total; le siguen, en orden de importancia, las clases de fabricación de cerveza (8.1\%), la de fabricación de aceites y grasas vegetales comestibles $(7.1 \%)$ en la agro-industria es también importante, y la fabricación de cigarros (5.4).

La fabricación de botanas también tiene una participación importante en la industria agroalimentaria. En promedio, en el periodo 1994-98 el valor de esta clase de alimentos fue poco más de 4.500 millones de pesos de 1994, participando con el $4.1 \%$ del valor de la producción total. Dentro de esta clases se ubican las papas fritas, las cuales participaron con más del $20 \%$ del valor de la clase. En general, durante el periodo presentado, la participación del valor de las papas fritas en el valor total de las manufacturas agroalimentarias osciló entre 0.8 y $1 \%$.

En relación al volumen de papas fritas producidas se observa que este ha ido en aumento, pues mientras que en 1994 fue de 37.8 mil toneladas, para 1998 ascendió a 55.9 mil toneladas; tal incremento representó un crecimiento anual del $10.2 \%$. La alta producción se debe a que el mercado nacional de frituras representa uno de los mercados más fuertes en el ámbito nacional donde el consumidor habitual de frituras destina una mayor parte de su ingreso a estos productos que incluyendo el destinado a alimentos básicos. En el Cuadro 10 se puede observar que en el periodo 1994-98, el valor generado por la producción de papas fritas fue casi igual al generado por la industria de congelados y empacados de carne fresca y por la industria de preparados y envasados de pescados y mariscos, y fue mayor, además, al valor generado por las industrias de beneficio de arroz y molienda de café.

La industrialización de la papa en México se lleva a cabo por dos tipos de empresas: la gran empresa, de carácter multinacional (como Sabritas y Barcel) y las pequeñas y medianas empresas mexicanas.

De acuerdo con información reportada por Figueroa (1998), durante 1997 las marcas Sabritas y Barcel concentraron el 70\% del total de las ventas, que en ese año ascendieron a 40 millones de pesos mexicanos. De las dos mega-agroindustrias, Sabritas que es parte de Frito-Lay International, la cual pertenece a Pepsico Inc., es la empresa líder en el mercado de las botanas de papas fritas. La proporción del mercado que cada una domina es diferente, con una clara predominancia de Sabritas, en una relación aproximada de 4:1 respecto a Barcel.

Sabritas sirve a más de 100 millones de consumidores en México y Centroamérica con botanas, y genera más de 15 mil empleos directos en México y América Latina. El éxito de las dos macroagroindustrias radica en la gran red de distribución que ambas empresas tienen, en el bajo costo de producción con el que operan, así como por sus programas de promoción. 
El efecto de esta rama agroindustrial en la economía mexicana puede ser analizada con base en los encadenamientos hacia adelante 0 hacia atrás que ella puede generar. Así la materia prima requerida para la producción proviene principalmente de productores nacionales, y se trata, por cierto, de un cultivo que a su vez tiene una demanda de mano de obra relativamente alta.

Para las características que debe reunir el producto, en cuanto a su estructura química interna y su aptitud para ser procesada, su calidad y su precio, puede hablarse de una "selección natural" de productores. Se trata principalmente de aquellos productores, generalmente grandes, que producen en las llamadas "tierras bajas". Tal es el caso de los pro-ducto-res del Pacífico y Centro Norte de México, y en menor escala, en el altiplano Central y Puebla. Son productores que cultivan la variedad "Atlantic" "Norteña" y/o "Herta", tipos de papa que tienen la textura y el contenido de harina y materia seca apropiada para el procesamiento industrial.

Sabritas ha incursionado en la llamada "agricultura de contrato" con productores, principalmente en el pacífico y Centro Norte de México, en su mayoría grandes productores, con una superficie mínima de 100 ha.

La "selección natural" entre los productores que acceden a este mercado se da por la calidad que deben reunir, por la cantidad mínima que ofrecen y por el precio a que pueden vender.

Los encadenamientos hacia adelante de esta rama industrial no existen, pues se trata de un producto de consumo final. Hay que señalar que el contenido nutritivo de este producto es escaso, o nulo.

Otros oferentes de papas fritas, que constituiría el restante $30 \%$ de las ventas anuales correspondieron a las pequeñas y medianas empresas que pertenecen a este sector. Dentro de este rubro se ubican alrededor de 500 empresas, las cuales tienen una reducida red de distribución del producto y ofrecen marcas propias, no tan reconocidas como las de las macroagroindustrias. Su abastecimiento proviene también de la producción nacional y generalmente por compras de mayoreo en las Centrales de Abasto.

\section{Personal empleado}

De acuerdo con los datos que arroja la Encuesta Industrial Mensual que levanta el INEGI, durante el periodo 1994-1998 el personal ocupado en la industria de alimentos, bebidas y tabaco durante todo el año fue de 352 mil personas en promedio. La clase de industria que presentó mayor demanda de mano de obra fue la industria de los refrescos absorbiendo el $23.1 \%$ del total de la población empleada; le siguieron, en orden de importancia, la preparación de azúcar (con el 9.7\%), la panadería y pastelería industrial (7.5\%), la preparación y envasado de frutas y legumbres (7.5) y la elaboración de galletas y pastas alimenticias $(5.0 \%)$, entre las más importantes. 
Cuadro 11. Valor de la producción y personal empleado en la agroindustria, promedio 1994-98

\begin{tabular}{|c|c|c|c|c|c|}
\hline \multirow[b]{2}{*}{ Clase } & \multirow{2}{*}{ 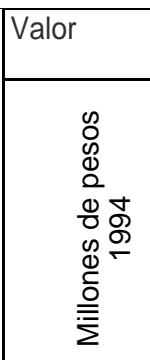 } & \multicolumn{2}{|c|}{ Personal empleado } & \multirow{2}{*}{ 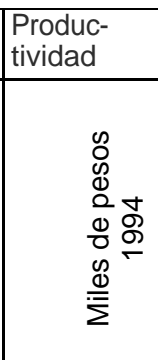 } & \multirow{2}{*}{\begin{tabular}{|l}
$\begin{array}{l}\text { Inten- } \\
\text { sidad }\end{array}$ \\
$\sum_{\underset{\alpha}{\infty}}$
\end{tabular}} \\
\hline & & 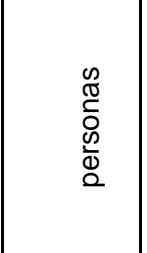 & $\%$ & & \\
\hline Total de la división & 109,413 & 352,051 & 100.0 & 310.8 & 3.2 \\
\hline $\begin{array}{l}\text { Congelado y empacado de } \\
\text { carne fresca }\end{array}$ & 1,018 & 3,721 & 1.1 & 273.5 & 3.7 \\
\hline $\begin{array}{l}\text { Preparación de conservas y } \\
\text { embutidos de carne }\end{array}$ & 3,118 & 12,906 & 3.7 & 241.6 & 4.1 \\
\hline $\begin{array}{l}\text { Preparación y envasado de frutas } \\
\text { y legumbres }\end{array}$ & 3,764 & 26,424 & 7.5 & 142.5 & 7.0 \\
\hline $\begin{array}{l}\text { Congelación y empaque de } \\
\text { pescados y mariscos frescos }\end{array}$ & 222 & 1,624 & 0.5 & 136.4 & 7.3 \\
\hline $\begin{array}{l}\text { Preparación y envasado de } \\
\text { conservas de pescados }\end{array}$ & 952 & 6,492 & 1.8 & 146.6 & 6.8 \\
\hline $\begin{array}{l}\text { Elaboración de galletas y pastas } \\
\text { alimenticias }\end{array}$ & 2,373 & 17,725 & 5.0 & 133.9 & 7.5 \\
\hline Panadería y pastelería industrial & 4,708 & 26,418 & 7.5 & 178.2 & 5.6 \\
\hline Fabricación de chicles & 1,059 & 4,794 & 1.4 & 220.9 & 4.5 \\
\hline $\begin{array}{l}\text { Elaboración de gelatinas, flanes y } \\
\text { postres en polvo para preparar }\end{array}$ & 370 & 1,666 & 0.5 & 222.2 & 4.5 \\
\hline $\begin{array}{l}\text { Elaboración de botanas y } \\
\text { productos de maíz no } \\
\text { mencionados }\end{array}$ & 4,505 & 15,566 & 4.4 & 289.4 & 3.5 \\
\hline Papas fritas & 990 & 3,422 & 1.0 & 289.4 & 3.5 \\
\hline $\begin{array}{l}\text { Vinificación (elaboración de } \\
\text { bebidas fermentadas de uva) }\end{array}$ & 243 & 1,034 & 0.3 & 234.6 & 4.3 \\
\hline $\begin{array}{l}\text { Elaboración de refrescos y otras } \\
\text { bebidas alcohólicas }\end{array}$ & 13,844 & 81,336 & 23.1 & 170.2 & 5.9 \\
\hline Beneficio de tabaco & 144 & 2,844 & 0.8 & 50.5 & 19.8 \\
\hline
\end{tabular}

${ }^{1}$ Personas empleadas para producir un millón de pesos de 1994.

Fuente: Elaborado con información obtenida de: INEGI. Encuesta Industrial Mensual (www.ineQi.qob.mx).

Las industrias que más personas emplean no necesariamente son las que mayor valor generan. Se observa que la productividad de la mano de obra varía entre los distintos tipos de industrias, oscilando entre un valor máximo de 1.107 millones de pesos por persona (correspondiente a la industria productora de cigarros) y un valor mínimo de 50.5 mil 
pesos por persona para la industria del beneficio del tabaco. La productividad de la mano de obra para la industria que elabora botanas fue de 289 mil pesos por persona, lo cual la ubica debajo de la productividad media de toda la industria de alimentos y bebidas.

Se podría decir que las industrias que generan más/menos valor por persona ocupada son las que hacen un uso más intensivo del capital/trabajo. Bajo este razonamiento, se tiene que la industria de fabricación de cigarros es la más intensiva en capital, puesto que 9 personas ocupadas al año generan 10 millones de pesos de 1994, en cambio en la industria de beneficio del tabaco sería necesario contratar a 198 personas para generar el mismo valor de producción. En el caso de la elaboración de papas fritas, 35 personas generan 10 millones de pesos

\section{Liberación Comercial Dentro del TLCAN}

Excepto para las papas frescas 0 refrigeradas para siembra (correspondiente a la fracción 07010101) que ya se encontraba libre de arancel cuando se llevó a cabo la negociación del TLCAN, se estableció un sistema de arancel cuota para las papas importadas de Estados Unidos y Canadá con plazos de desgravación arancelaria de hasta 10 años. La descripción del sistema arancel-cuota, así como los plazos de desgravación se presenta a continuación.

Papas frescas o refrigeradas para los demás usos (07019099)._Para esta fracción México aplica un arancel-cuota sobre los bienes originarios provenientes de Estados Unidos comprendidos en esta fracción de acuerdo a lo siguiente:(a) México permitirá que un cupo mínimo anual proveniente de Estados Unidos se importe libre de arancel y, (b) sobre la importación que exceda este cupo, México podrá aplicar un arancel de acuerdo con la tasa base y la categoría de desgravación especificadas para cada fracción. El cupo mínimo será de 15,000 toneladas métricas en 1994 y a partir de 1995 se incrementará cada año en $3 \%$ respecto al cupo anterior.

Para Canadá, México aplicará un arancel-cuota sobre los bienes provenientes de este país comprendidos en esta fracción, de acuerdo a lo siguiente:(a) México permitirá que un cupo mínimo anual proveniente de Canadá se importe libre de arancel y, (b) sobre la importación que exceda dicho cupo, México podrá aplicar un arancel de acuerdo con la base y la categoría de desgravación especificados para cada fracción. El cupo mínimo será de 4,000 t en 1994 y a partir de 1995 se incrementará cada año en 3\% respecto al cupo anterior.

En relación a la desgravación, la tasa base para los bienes comprendidos en esta fracción provenientes de los Estados Unidos y Canadá será la mayor de dos tasas: $272 \%$ ad valorem ó 0.354 dólares por kilogramo. El arancel aduanero aplicable a los bienes originarios comprendidos en esta fracción será el mayor de:(a) la tasa base de $272 \%$ ad valorem, reducida 
de acuerdo con la categoría de desgravación correspondiente y, (b) la tasa base de 0.354 dólares por kilogramo, reducida de acuerdo con la categoría de desgravación correspondiente.

La desgravación correspondiente, será en diez etapas anuales a partir del $1^{\circ}$ de enero de 1994, de tal manera que quede libre de arancel a partir del $1^{\circ} \mathrm{de}$ enero del 2003.

Papas cocidas en agua 0 al vapor, congeladas (07101001). De conformidad con el artículo 703.3 y hasta el 31 de diciembre del 2002, México podrá aplicar una salvaguardia especial en la forma de arancelcuota sobre los bienes originarios provenientes de los Estados Unidos comprendidos en esta fracción de acuerdo a lo siguiente: (a) México permitirá que un cupo mínimo anual proveniente de Estados Unidos se importe sujeto al arancel aduanero resultante de una tasa base de $15 \%$ en categoría de desgravación C y, (b) sobre la importación que exceda de dicho cupo, México podrá aplicar una tasa arancelaria que no exceda de la menor de las dos tasas: $15 \%$ ad valorem o la tasa de nación favorecida prevaleciente. El cupo mínimo será de 1,800 toneladas métricas en 1994 y a partir de 1995 se incrementará cada año en 3\% con respecto al cupo anterior.

De conformidad con el artículo 703.3 y hasta el 31 de diciembre del 2002 , México podrá aplicar una salvaguardia especial en la forma de arancel-cuota sobre los bienes originarios provenientes de Canadá comprendidos en las fracciones 07101001 y 07121001 de acuerdo a lo siguiente:(a) México permitirá que un cupo mínimo anual agregado proveniente de Canadá para las fracciones mencionadas se importe sujeto al arancel aduanero resultante de una tasa base correspondiente en categoría de desgravación C y, (b) sobre la importación agregada para las dos fracciones que exceda de dicho cupo, México podrá aplicar una tasa arancelaria que no exceda de la menor de dos tasas: la tasa base correspondiente o la tasa de nación más favorecida prevaleciente. El cupo mínimo agregado será de 1,000 toneladas métricas en 1994 y a partir de 1995 se incrementará cada año en 5\% con respecto al cupo anterior.

En relación a la desgravación, la tasa base para los bienes comprendidos de Estados Unidos y Canadá será de $20 \%$ en un periodo de desgravación de diez etapas anuales, comenzando el $1^{\circ}$ de enero de 1994 , de tal manera que el producto en cuestión quede libre de arancel a partir del $1^{\circ}$ de enero del año 2003.

\section{Conclusiones y Reflexiones Finales}

Durante el periodo de 1978-97 la producción y el consumo de papa presentaron una tasa de crecimiento media anual del 1.42 y $1.67 \%$, respectivamente. El crecimiento de la producción Üsf explica fundamentalmente por el crecimiento de los rendimientos por hectárea. 
en tanto que el aumento del consumo se explica por el crecimiento de la población.

Suponiendo que dicho ritmo de crecimiento se mantenga en años futuros, se tiene que para el año 2005 la producción de papa ascendería a 1.47 millones de toneladas, en tanto que el consumo sería de 1.55 millones de toneladas (Cuadro 12).

Cuadro 12. Proyección ${ }^{1}$ de la producción, consumo e importaciones de papa al año 2005

\begin{tabular}{|l|ccccccccc|}
\hline Indicador & \multicolumn{10}{|c|}{ Miles de toneladas } \\
\cline { 2 - 10 } & 1997 & 1998 & 1999 & 2000 & 2001 & 2002 & 2003 & 2004 & $\mathbf{2 0 0 5}$ \\
\hline Producción & 1,317 & 1,335 & 1,354 & 1,374 & 1,393 & 1,413 & 1,433 & 1,454 & $\mathbf{1 , 4 7 4}$ \\
Consumo & 1,360 & 1,382 & 1,405 & 1,429 & 1,453 & 1,477 & 1,502 & 1,527 & $\mathbf{1 , 5 5 2}$ \\
Importaciones & $\mathbf{4 3}$ & $\mathbf{4 7}$ & $\mathbf{5 1}$ & $\mathbf{5 5}$ & $\mathbf{6 0}$ & $\mathbf{6 4}$ & $\mathbf{6 9}$ & $\mathbf{7 3}$ & $\mathbf{7 8}$ \\
& & & & & & & & &
\end{tabular}

1 Proyección realizada usando la tasa de crecimiento media anual de la producción y el consumo, de 1.42 y $1.67 \%$, respectivamente, registrada durante el periodo 1978/1980-1995/1997.

Fuente: Elaborado con información obtenida de: SAGAR. Varios años. Anuario estadístico de la producción agrícola de los Estados Unidos Mexicanos. México, D.F. FAOSTAT (www.apps.fao.org).

La mayor tasa de crecimiento del consumo, respecto a la de la producción, explica el incremento de las importaciones, que para el año 2005 serían de 78 mil toneladas, lo cual representaría un incremento del $81.4 \%$, respecto a las importaciones registradas en 1997.

Es importante mencionar que un incremento en el consumo per cápita de la papa, sin medidas simultáneas que aumenten la producción, incrementaría las importaciones. Igualmente es pertinente mencionar que un incremento en la producción tiene efectos favorables en el mercado de trabajo, tanto en la producción de papa, como en su procesamiento. Ambos procesos son relativamente intensivos en el uso de mano de obra.

Durante el periodo 1994-98 la agroindustria de la papa se caracterizó por presentar un fuerte dinamismo, ya que el valor de la producción creció en 189 millones de pesos de 1994, lo cual representó un crecimiento anual del $4.7 \%$. Suponiendo un crecimiento anual en la misma magnitud se tiene que para el año 2005 el valor de la producción de la industria sería de 5,394 personas, lo cual sería equivalente a un crecimiento anual $6.7 \%$. Esta tasa sería sensiblemente mayor a la tasa de crecimiento de la 
población, la cual según el Consejo Nacional de Población (1995) sería del $1.5 \%{ }^{1}$ anual en el periodo 1995-2005. También sería mayor a la tasa promedio de absorción de mano de obra por el sector industrial en los últimos años.

Por otra parte, el comercio exterior de papa presenta algunas características que es pertinente tener presente. Por un lado la papa ha sido importada en México bajo diferentes formas y tanto como insumo para la producción agrícola, como para el consumo humano directo. Por otro lado, se trata de un producto de baja densidad económica, que para que sea atractivo comerciar debe hacerse bajo condiciones favorables competitivas $y / 0$ con presentaciones y algún grado de procesamiento que no exista en el mercado de destino. Ambas características se han dado en el mercado mexicano, situación que explica el incremento en las importaciones de años recientes.

La producción nacional para la agroindustria es considerable. Mantener este mercado exige calidad y precio, factores que hasta ahora sólo los grandes productores han aportado, el Instituto Nacional de Investigaciones Forestales y Agropecuarias de México (INIFAP) ha liberado una variedad de características idóneas para su procesamiento: la variedad "Norteña". Sin embargo, debido al precio que los compradores pagan en el mercado, éste ha sido reservado para los productores más eficientes, que han sido los medianos y los grandes, ubicados generalmente en el Norte, Pacífico y Centro de México. Se trata también de productores en regiones cercanas a las plantas procesadoras.

Las exportaciones mexicanas de papa se han dirigido fundamentalmente a sus vecinos del sur más próximos. Belice absorbe más del $90 \%$ de las exportaciones. Se trata generalmente de exportaciones de papa fresca.

A través de las agroindustrias transnacionales que operan en México, Sabritas y Barcel, sería posible pensar en una expansión de las exportaciones, que podría ser de carácter intra-industrial, o bien, para los consumidores finales de aquellas localidades donde tienen plantas distribuidoras. Aquí sería el caso principalmente de los países centroamericanos, pues en los países sudamericanos hay oferentes cercanos. Otra institución que podría jugar un papel importante en el contexto de fomentar las exportaciones es la asociación de productores de papa. En cualquier caso, es fundamental que los productores mexicanos muestren mayor eficiencia que los productores del lugar de destino de las exportaciones.

Finalmente, en el marco del análisis del proceso de agroindustrialización en el crecimiento de la economía, sería pertinente tener presente que el

1 La tasa de crecimiento se obtiene utilizando como valor inicial la población de 1995, reportada por el Censo de Población de ese año (INEGI) y como valor final la población proyectada por CONAPO (1995) al año 2005. 
desarrollo de la agroindustria de la papa, o de la agroindustria en general, impone nuevos senderos a la agricultura, y con ello también al marco institucional en que opera la política agrícola en un país. Ello es así porque en el proceso de industrialización de la producción agrícola, esa producción debe de reunir normas de calidad, puntualidad y eficiencia, como requisito para subsistir como proveedora de la industria. Es decir, la producción agrícola se convierte en un insumo de la agroindustria y para que la industria funcione, ese insumo debe estar en calidad, cantidad y tiempo, que permitan a la industria funcionar y ser competitiva en una economía abierta.

En el caso de la agroindustria de la papa, su procesamiento en hojuelas o en papas a la francesa, por ejemplo, requiere de una papa con un contenido específico de materia seca, situación que implica el uso de sólo ciertas variedades de papa, que van unidas a una tecnología de producción y de manejo del cultivo. , - $^{-}$

Esas condiciones de producción y de abastecimiento que la agricultura debe proporcionar, y de los que depende el funcionamiento de la agroindustria, conlleva la necesidad de cambios en el modo de hacer agricultura. Esos cambios trascienden la esfera de las tecnologías de producción y del manejo del cultivo agrícola. Son cambios que han significado con frecuencia la necesidad de hacer modificaciones en el marco legal y en general del contexto institucional en que opera la agricultura. Tal es el caso de la reforma del artículo 27 constitucional, en México, que tuvo por objeto flexibilizar las relaciones entre el capital y la tierra en la agricultura, también las relaciones entre los productores agrícolas entre el capital y la tierra en la agricultura, también las relacione entre los productores agrícolas y el Estado, así como el manejo que hacen de sus recursos para la producción (Téllez Kuenzler, 1994).

En el mismo sentido se han originado cambios en instituciones relevantes de la economía agrícola, que han posibilitado, o formalizado la incursión de las empresas agroindustrializadoras en la agricultura de contrato, 0 en la producción directa que llevan a cabo las agroindustrias, de los productos agrícolas que posteriormente procesan. Se han promovido así nuevas figuras legales que han respondido a las necesidades de la agroindustrialización en el campo mexicano (Muñoz Rodríguez y Santoyo Cortés, 1994; Rueda Peiro, 1997), bajo condiciones rentables para las empresas agroindustrializadoras.

Es pertinente tener presente que la participación de los productores agrícolas en una economía abierta, y en una economía que industrializa la producción agrícola, implica nuevas exigencias y normas de comportamiento que deben observar los productores. Los requisitos exigidos y los retos que se plantean a la producción agrícola van desde forma y composición química de la producción (como en el caso de la papa, con el contenido de materia seca requerida para su procesamiento), normas fitosanitarias a cubrir y que son exigidas por las 
normas del mercado de destino, calidad de la producción, regularidad y puntualidad en el abastecimiento, eficiencia en cuanto a precios, etc. El cumplimiento de tales exigencias incidirá sobre su éxito como productores y sobre su permanencia en el mercado, a la vez que influirá en el proceso de agroindustrialización.

Por las condiciones que deben reunirse en la producción y en el abastecimiento de la papa fresca, sea para el mercado interno o externo, para el consumo directo o para su procesamiento, es de esperarse que la participación de los productores de papa será seleccionada por el mercado. Pero en la heterogeneidad que impera al interior de la producción de papa en México, habrá necesidad de reasignar los recursos que saldrán de la producción de papa, hacia cultivos que el mercado demande y para los productos con perspectivas. En el interior de esa estructura de productores paperos mexicanos, son necesarios instrumentos diferenciados, que ataquen la situación específica y respondan a los requerimientos para ser productores competitivos, según el estrato de productores de que se trate. Esos requerimientos desencadenarían acciones en la política agrícola, en el diseño de instrumentos de diversa índole, relativos a la tecnología de producción, los canales de comercialización la distribución del producto, el financiamiento de la producción y de la distribución, la organización de los productores, tanto para la producción, el abasto de insumos, la distribución o el procesamiento del producto. En suma, es necesario que la política agrícola proporcione un tratamiento integral y bajo la perspectiva de una cadena económica al cultivo papa.

El éxito de la política agrícola tendrá que ver con el reconocimiento específico de la problemática que tienen los productores con potencial, o los instrumentos que conciba para reasignar los recursos, tanto la tierra como la mano de obra de aquellos productores que no puedan seguir en el mercado. En el estrato de productores cuyas perspectivas no ofrezcan posibilidades de una producción rentable en la producción de papa, los recursos que la política agrícola asigne tendrían que ir encaminados a reconvertir a esos productores, aunque esa reconversión no necesariamente pudiera quedar ubicada en la producción agrícola, pues habría necesidad de analizar el problema en forma integral, incluyendo también la participación en otra fase del proceso de distribución o comercialización de la producción, o también en el mercado de trabajo.

\section{Bibliografía}

Apoyos y Servicios a la Comercialización Agropecuaria (ASERCA). 1998. Claridades agropecuarias. Número 57. México, D.F.

Consejo Nacional de Población (CONAPO). 1995. Estimación de la población base y proyecciones de población 1990-2030. México, D.F.

FAOSTAT. www.apps.fao.org 
Figueroa, K. 1998. Análisis de la evolución de la macroagroindustria en México, en el periodo 1988-1996. Tesis de Licenciatura. Universidad Autónoma Chapingo, 220p.

Instituto Nacional de Estadística, Geografía e Informática. 1997. Conteo de población y vivienda 1995. Aguascalientes, México.

Muñoz Rodríguez, M. y V.H. Santoyo Cortés. 1994. Visión y Misión Empresarial. Competencia y Cooperación en el Medio Rural. Universidad Autónoma Chapingo, 324p.

Quaim, M. 1998. Transgenic virus Resistant Potatoes in México: Potential socioeconomic Implications of a North-South Biotechnology Transfer. .Mimeo, 63p.

Rueda Peiro, I. 1997. Las empresas integradoras en México. México, 236p.

SAGAR-INIFAP. 1997. Programa Nacional de Investigación en el cultivo de la Papa. Publicación Especial No. 13. ' $¿$ :

Santiago. M.J. y J. Ruvalcaba Limón. 1995 "Competitividad de los productores en los llanos de Puebla en una economía abierta". En: A. Biarnés, J.Ph.Colin, M.J.Santiago Cruz. 1885, Agroeconomía de la papa en México. Orstom/Colegio de Postgraduados, pp. 179-189.

Téllez Kuenzler, L. 1994. La modernización del sector agropecuario y forestal. México 1994. 307p 